\title{
Pandemic Preparedness Against Influenza: DNA Vaccine for Rapid Relief
}

\author{
Tor Kristian Andersen ${ }^{1}$, Johanna Bodin ${ }^{2}$, Fredrik Oftung ${ }^{2}$, Bjarne Bogen ${ }^{1,3}$, Siri Mjaaland ${ }^{2}$ \\ and Gunnveig Grødeland ${ }^{1,3 *}$
}

${ }^{1}$ Department of Immunology and Transfusion Medicine, Institute of Clinical Medicine, University of Oslo, Oslo, Norway, ${ }^{2}$ Division for Infection Control and Environmental Health, Norwegian Institute of Public Health, Oslo, Norway, ${ }^{3}$ Department of Immunology and Transfusion Medicine, Clinic for Laboratory Medicine, Oslo University Hospital, Oslo, Norway

\section{OPEN ACCESS}

Edited by:

Corey Patrick Mallett,

GlaxoSmithKline, United States

Reviewed by:

Domenico Tortorella,

Icahn School of Medicine at Mount

Sinai, United States

Teodor Doru Brumeanu,

Uniformed Services University of the

Health Sciences, United States

${ }^{*}$ Correspondence:

Gunnveig Grødeland

gunnveig.grodeland@medisin.uio.no

Specialty section:

This article was submitted to

Vaccines and Molecular Therapeutics,

a section of the journal

Frontiers in Immunology

Received: 25 July 2021 Accepted: 20 September 2021

Published: 08 October 2021

Citation:

Andersen TK, Bodin J, Oftung F,

Bogen B, Mjaaland $S$ and

Grødeland G (2021) Pandemic

Preparedness Against Influenza: DNA

Vaccine for Rapid Relief.

Front. Immunol. 12:747032.

doi: 10.3389/fimmu.2021.747032
The 2009 "swine flu" pandemic outbreak demonstrated the limiting capacity for eggbased vaccines with respect to global vaccine supply within a timely fashion. New vaccine platforms that efficiently can quench pandemic influenza emergences are urgently needed. Since 2009, there has been a profound development of new vaccine platform technologies with respect to prophylactic use in the population, including DNA vaccines. These vaccines are particularly well suited for global pandemic responses as the DNA format is temperature stable and the production process is cheap and rapid. Here, we show that by targeting influenza antigens directly to antigen presenting cells (APC), DNA vaccine efficacy equals that of conventional technologies. A single dose of naked DNA encoding hemagglutinin (HA) from influenza/A/California/2009 (H1N1), linked to a targeting moiety directing the vaccine to major histocompatibility complex class II (MHCII) molecules, raised similar humoral immune responses as the adjuvanted split virion vaccine Pandemrix, widely administered in the 2009 pandemic. Both vaccine formats rapidly induced serum antibodies that could protect mice already 8 days after a single immunization, in contrast to the slower kinetics of a seasonal trivalent inactivated influenza vaccine (TIV). Importantly, the DNA vaccine also elicited cytotoxic T-cell responses that reduced morbidity after vaccination, in contrast to very limited T-cell responses seen after immunization with Pandemrix and TIV. These data demonstrate that DNA vaccines has the potential as a single dose platform vaccine, with rapid protective effects without the need for adjuvant, and confirms the relevance of naked DNA vaccines as candidates for pandemic preparedness.

Keywords: pandemic, vaccine, DNA vaccine, APC, APC-targeting, influenza, inactivated vaccine

\section{INTRODUCTION}

Vaccines are highly efficient at prophylactic relief against infectious diseases, and vaccines against influenza, measles, and tuberculosis are examples of vaccines that annually save many lives $(1,2)$. The current SARS-CoV-2 pandemic has once again reminded us of the dependency on effective vaccines for control of a pandemic outbreak. In 2009, it became clear that the use of conventional 
influenza vaccines based on egg-production had several shortcomings. In particular, the production time was prolonged, hampering efficient use even in a situation where the correlate of protection was well established, and approved vaccines against influenza were easily available $(3,4)$. For pandemic control, rapid availability of well-matched vaccines is key $(5-7)$.

In 2009, the conventional vaccines against pandemic influenza was produced within 6 months, which represents a record fast production for this vaccine format (8). Thus, it should be no surprise that the frontrunner vaccines developed against SARS-CoV-2 in 2020 were based on more versatile technologies (9-11). In this study, we have compared the immunogenicity and efficacy of conventional influenza vaccines to that of a novel DNA vaccine format. DNA vaccines are rapid to produce, easy to store and deploy independent of a cold chain, and highly versatile with respect to updating the vaccine to match new antigenic variants (12). Furthermore, the development of minimally invasive DNA vaccine delivery systems, such as microneedle patches $(13,14)$ or needle-free jet delivery $(15$, 16), makes naked DNA vaccines highly applicable in a mass vaccination scenario.

While DNA vaccines against influenza has been in development since the 1990's with promising data in preclinical models, there are limited data from clinical trials due to low immunogenicity in larger animals (17). Some recent breakthrough has countered this, and most of the clinically approved DNA vaccines are based on delivery with viral vectors $(11,18,19)$. While viral vector delivered DNA vaccines are attractive, the viral vector may in itself pose a risk for development of adverse events (20), and immune responses against the vector backbone may hamper repeated use, e.g. in prime boost vaccination schedules or updates for emerging viral variants.

Previously, we have developed a novel DNA vaccine format where the antigen was genetically linked to a targeting moiety specific for a selected receptor on antigen presenting cells (APC) (21-23). In brief, following delivery of naked DNA plasmids encoding the APC-targeted antigen under a single promotor, the cells at the injection site will secrete the corresponding proteins. The APC-specific targeting moiety will then direct the vaccine proteins specifically to the most relevant cells, and as such greatly enhance vaccine immunogenicity and efficacy (21-23). Of note, we have previously observed that steering of the APC-targeted vaccines to different APC receptors can polarize immune responses to either dominant antibody responses/Th2 or cellular responses/Th1 (24). As such, this vaccine platform could be tailored for enhanced induction of the most relevant correlate of protection for any disease (24-26). For influenza, the main correlate of protection against infection are neutralizing antibodies against the HA protein. We have previously found that targeting of HA to major histocompatibility complex class II (MHCII) molecules was superior at raising protective antibodies following vaccination, as compared to eight other APC specific targeting moieties ( $\alpha$ CD11c, $\alpha$ CD 40 , Xcl-1, MIP- $1 \alpha$, FliC, GMCSF, Flt-3L, $\alpha$ DEC205) (27). Hence, we have here used a plasmid encoding MHCII-targeted HA molecules for vaccination of mice $(23,28)$. Previously, such vaccination have demonstrated full protection against lethal influenza challenges in mice up to about a year after a single DNA vaccination $(22,24)$, as well as demonstrated promising efficacy in larger animals (23).

We have here compared the formation of immune responses in mice following vaccination with this MHCII-targeted DNA vaccine to that of conventional influenza vaccines. More specifically, we compared the MHCII-targeted DNA vaccine to Pandemrix, an adjuvanted inactivated split virion vaccine widely administered to counter the 2009 influenza pandemic, as well as the corresponding non-adjuvanted inactivated trivalent influenza vaccine (TIV) from the 2018/19 season.

We show that a single delivery of the MHCII-targeted DNA vaccine raised antibody responses similar to the adjuvanted Pandemrix, and both vaccines could offer long-lasting protection against a lethal influenza challenge. Interestingly, the MHCII-targeted DNA vaccine proved better than Pandemrix with respect to offering protection against a lethal influenza challenge one week after a single vaccination. This protection was likely attributed to the ability of the MHCIItargeted vaccine to also raise protective $\mathrm{T}$ cell responses.

\section{MATERIALS AND METHODS}

\section{Mice and Cell Lines}

Female BALB/c mice aged 6-8 weeks (Janvier, le Genest-SaintIsle, France) were used in all experiments. All experiments involving research animals were pre-approved for ethics by the Norwegian Food Safety Authority. Cell work was performed with human embryonic kidney 293E cells purchased from the American Type Culture Collection (ATCC; Manassas, VA, USA).

\section{Vaccines and Vaccination}

Anesthetized mice [0.1mg/10g: cocktail of Zoletil Forte (250mg/ ml; Virbac France), Rompun (20mg/ml; Bayer Animal Health $\mathrm{GmbH})$, and fentanyl $(50 \mu \mathrm{g} / \mathrm{ml}$; Actavis, Germany)] were vaccinated intra muscularly (i.m.) with $25 \mu \mathrm{g}$ DNA ( $\alpha$ MHCIIHA) into each quadriceps femoris, immediately followed by electroporation over the injection site (Elgen; Inovio Biomedical Co., Blue Bell, PA). The $\alpha$ MHCII-HA plasmid encodes HA from influenza A/California/07/2009 (H1N1), aa 18-541, linked to the MHCII-specific scFv via a dimerization unit consisting of the $\mathrm{C}_{\mathrm{H}} 3$ domain of human IgG3 (22). All DNA vaccines were purified by using an EndoFree Plasmid Mega kit (catalog no. 12381; Qiagen, Hilden, Germany) and dissolved in sterile injection fluid $(0.9 \% \mathrm{NaCl})$. Alternatively, anaesthetized mice were vaccinated i.m. with $1 / 10$ human dose of Pandemrix with AS03 adjuvant (GlaxoSmithKline, Belgium), or a nonadjuvanted trivalent inactivated seasonal influenza vaccine [strains: A/Michigan/45/2015 (H1N1)pdm09-like virus, A/ Singapore/INFIMH-16-0019/2016(H3N2)-like virus B/ Colorado/06/2017-like virus (B/Victoria/2/87 lineage)]. 


\section{Viral Challenge}

Mice were anaesthetized as described above, and a $5 \mathrm{xLD}_{50}$ dose of A/California/07/2009(H1N1) delivered in $10 \mu \mathrm{l}$ into each nostril. Mice were monitored daily for weight loss and euthanized at $80 \%$ of the original body weight. In figures, euthanized mice are scored as $80 \%$ for the remaining experimental time.

\section{Flow Cytometry and Imaging}

Draining LNs (iliac) were harvested and single cell suspensions prepared by GentleMACS dissociator (Miltenyi Biotech, Germany). Cells were stained with anti-CD3 (75-0032, Tonbo biosciences, San Diego, CA, USA), anti-GL7 (144603, Tonbo), anti-CD38 (102718, Tonbo), and anti-B220 (552771, BD Biosciences, Franklin Lakes, NJ, USA). HA reactivity was evaluated by binding to a His-tagged recombinant HA (Cal07) protein with an $\mathrm{Y} 98 \mathrm{~F}$ substitution (29) (rec.HA ${ }^{\mathrm{Y} 98 \mathrm{~F}}$ ), detected by anti-6xHis mAb (ab133714, Abcam, Cambridge, England). All samples were analyzed using an Attune NxT flow cytometer (Thermo Fisher Scientific, Waltham, MA, USA) and FlowJo software (ver.10).

Draining LNs were embedded in OCT mounting medium (00411243, Q Path, VWR, Radnor, PA, USA), immediately frozen on dry ice and stored at $-80^{\circ} \mathrm{C}$. Six-micrometer sections were collected on glass slides, air dried, fixed in room temperature acetone for $5 \mathrm{~min}$, air dried, and blocked in 30\% normal rat serum with $\mathrm{FcR} \gamma$ blocking reagent $(10 \mu \mathrm{g} / \mathrm{ml}$, HB197). Sections were then incubated with $2 \mu \mathrm{g} / \mathrm{ml} \mathrm{rec.HA}^{\mathrm{Y} 98 \mathrm{~F}}$, followed by rabbit anti-HA(Cal07) pAb (11085-T54, Sino Biological, Inc) and anti-GL7-PE (144608, BioLegend, San Diego, CA, USA). Finally, colors were amplified using antiFITC-Alexa Fluor 488 (A-11090, Thermo Fisher Scientific) and anti-R Phycoerythrin-Texas Red (ab34734, Abcam), and counterstained with DAPI. Sections were mounted with ProLong Diamond Antifade Mountant (P36970, Thermo Fisher Scientific). Images were acquired in a Nikon Eclipse Ti microscope using a Nikon S Plan Fluor 20x objective with a 0.60 numerical aperture and a Nikon Digital Sight Camera. All micrographs were analyzed and processed using ImageJ Version: 2.0.0-rc-69/1.52p, Build: 269a0ad53f.

\section{Serum ELISA and Avidity Index ELISA}

Blood was harvested by puncture of the saphenous vein, and sera collected by centrifugation. ELISA plates (Costar 5390, Corning, Corning, NY) were coated with $0.5 \mu \mathrm{g} / \mathrm{ml} \mathrm{rec.} \mathrm{HA} \mathrm{from} \mathrm{A/}$ California/07/2009 (11085-V08H, Sino Biological, Inc., Wayne, PA, USA), blocked with $2 \% \mathrm{BSA} / \mathrm{PBS}$, and incubated with serially diluted serum samples assayed for individual mice. Captured serum antibodies were detected with anti-mouse IgG1-bio (553500, BD Pharmingen, San Diego, CA, USA), or anti-mouse IgG2a- bio (553502, BD Pharmingen), and streptavidin-alkaline phosphatase (RPN1234, GE Healthcare, Buckinghamshire, UK), or alkaline phosphatase conjugated goat anti-mouse IgG (A2429, Saint-Louis, MO, USA). Plates were developed with phosphatase substrate (P4744, Sigma-Aldrich).
Resistance to UREA wash was used to calculate avidity index. Captured serum antibodies were incubated for $10 \mathrm{~min}$ with $2 \mathrm{M}$ UREA or PBS before detecting remaining serum antibodies with alkaline phosphatase conjugated goat anti-mouse IgG (A9316, Sigma Aldrich). AUC was calculated for the dilution curves and baseline for AUC was calculated based on $\mathrm{NaCl}$ serum levels. Avidity index is defined as AUC for samples treated with UREA divided by AUC for the corresponding PBS treated sample.

\section{ELISpot Assay}

Bone marrow was harvested from femur and tibia. Single cell suspensions were prepared and seeded on MultiScreen HTS filter plates (MSIPS45, Merck Millipore Ltd., Tullagreen, Ireland) precoated overnight at $4^{\circ} \mathrm{C}$ with $0.5 \mu \mathrm{g} /$ well of rec.HA (Cal07) (11085-V08H, Sino Biological), and incubated for 20h. Spots were detected with anti-mouse IgG (A1418, Sigma-Aldrich), developed with phosphatase substrate (P4744, Sigma-Aldrich) and analyzed in CTL- ImmunoSpot ${ }^{\circledR}$ analyzer (CTL, Shaker Heights, OH, USA).

\section{In Vivo Cellular Cytotoxicity Assay}

In vivo cellular cytotoxicity assay were adapted from Durward et al. (30). In brief, splenocytes were harvested and single cell suspensions prepared. Splenocytes were incubated with the MHC class I restricted influenza HA (Cal07) peptide IYSTVASSL, the NP peptide (RLIQNSLTIERMVLS), or a negative control peptide, at a density of $5 \times 10^{7}$ cells $/ \mathrm{mL}$ for $1 \mathrm{~h}$ at $4^{\circ} \mathrm{C}$ followed by $30 \mathrm{~min}$ incubation at $37^{\circ} \mathrm{C}$. Peptide-loaded cells were washed twice in PBS and subsequently stained with 5 $\mu \mathrm{M}$ CellTrace Violet (CTV) (C34557, Life Technologies) (HA peptide loaded cells), or $1 \mu \mathrm{M}$ CellTrace Far Red (CTFR) (C34564, Life Technologies) (NP peptide loaded), or double stain (CTV and CTFR) (negative control) at a density of $5 \times 10^{7}$ cells $/ \mathrm{mL}$ for $20 \mathrm{~min}$ at $37^{\circ} \mathrm{C}$. Cells were mixed in equal ratios (1:1:1), and a total of $15 \times 10^{6}$ cells injected i.v. in a $100 \mu$ volume to vaccinated mice. Spleens were harvested $16 \mathrm{~h}$ later, single cell suspensions prepared, and the presence of peptide loaded cells investigated by flow cytometry. The ratio of CTV to CTV/CTFR or CTFR to CTV/CTFR cells were calculated as \% specific lysis = [ 1 - (average ratio in group with $\mathrm{NaCl}$ vaccinated mice/ experimental ratio)].

\section{In Vitro T Cell Stimulation and Cytokine Staining}

Spleens from mice were collected 9 and 21 days after vaccination and homogenized through a wire mesh to get a single cell suspension by Lympholyte M (Cedarlane, Burlington, US) gradient centrifugation, and thereafter kept frozen in Fetal Bovine Serum (FBS, Sigma/Merck) with 10\% DMSO (Sigma/ Merck) at $-150^{\circ} \mathrm{C}$. Splenocytes were thawed, washed in RPMI 1640 (Gibco, Thermo Fischer Scientific) with 10\% FBS (Sigma/ Merck) and rested for 24 hours prior to stimulation with $5.6 \mu \mathrm{g}$ $\mathrm{HA} / \mathrm{ml}$ (400HAU) of A/California/07/2009 (H1N1) for 4 hours at $37^{\circ} \mathrm{C}$ in the presence of $2.5 \mu \mathrm{g} / \mathrm{ml}$ brefeldin A (BFA, Sigma/ Merck). Positive control was stimulated with $50 \mathrm{ng} / \mathrm{ml}$ phorbol myristate acetate (PMA, Sigma/Merck) and $1 \mu \mathrm{g} / \mathrm{ml}$ ionomycin (Sigma/Merck). Cells were stained for viability (Live/dead aqua, 
Molecular Probes, Thermo Fischer Scientific) and extracellular markers in Brilliant staining buffer (BD Biosciences, San Antonia, CA, US) (each staining for 30 minutes at room temperature), then fixed and permeabilized ( 45 minutes at $4^{\circ} \mathrm{C}$ using Foxp3 fixation and permeabilization kit, eBioscience) prior to intracellular staining $\left(1\right.$ hour $\left.4^{\circ} \mathrm{C}\right)$. Percentage of positive CD3, CD4, CD8, CD44, CD62L, CD25, CD19, CD49b, Foxp3, CD107a, IFN $\gamma$, TNF $\alpha$, IL-2 and IL-17A cells was analysed on a ZE5 flow cytometer (Bio-Rad, CA, US). Fractions of memory T cells; T effector memory (TEM) $\mathrm{CD}_{4} 4^{+} \mathrm{CD} 62 \mathrm{~L}^{-}$, and $\mathrm{T}$ central memory (TCM) $\mathrm{CD} 44^{+} \mathrm{CD}_{2} \mathrm{~L}^{+}$, and naïve $\mathrm{T}$ cells $\mathrm{CD} 44$ $\mathrm{CD}_{2} \mathrm{~L}^{+}$as well as NK and NKT cells were also assessed using FlowJo_V10 (Tree Star, San Carlos, CA, US).

Splenocytes were harvested 21 days after vaccination, and single cell suspensions rested for 24 hours prior to stimulation with $5.6 \mu \mathrm{g} \mathrm{HA} / \mathrm{ml}$ (400HAU) A/California/07/2009 (H1N1) for 4 hours at $37^{\circ} \mathrm{C}$ in the presence of $2.5 \mu \mathrm{g} / \mathrm{ml}$ brefeldin A (BFA, Sigma). Splenocytes were then stained for identification of IFN $\gamma$, IL-2, and TNFo positive CD4 and CD8 T-cells.

\section{Statistical Analysis}

The p-values represent exact values calculated by unpaired nonparametric two-tailed Mann-Whitney tests. Weight curves were analyzed with two-way ANOVA, and survival curves with the Gehan-Breslow-Wilcoxon test. Statistical analysis of flow cytometry was performed using one-way ANOVA with the Holm-Sidiak multiple-comparison test. All analysis was performed using GraphPad Prim 9 software.

\section{RESULTS}

\section{Induction of Strong and Long Lasting Protective Antibodies up to 6 Months After a Single Vaccination}

In order to compare the antibody kinetics of different vaccine strategies, we vaccinated mice once i.m. with either TIV, Pandemrix, or the MHCII-targeted DNA vaccine ( $\alpha$ MHCIIHA). Both Pandemrix and $\alpha$ MHCII-HA are monovalent vaccines, designed to protect against A/California/07/2009 (H1N1), whereas TIV in addition to a pdm09 like strain contains an $\mathrm{H} 3 \mathrm{~N} 2$ strain and an influenza B strain. The plasmids encoding $\alpha$ MHCII-HA were formulated in a physiological saline solution $(\mathrm{NaCl})$, while Pandemrix was formulated with the adjuvant solution AS03. Thus, both saline and AS03 were used as experimental negative controls.

Following a single vaccination with the different vaccines, serum samples were collected and monitored for HA specific antibodies over 180 days. Both $\alpha$ MHCII-HA and Pandemrix rapidly generated high titers of Cal07 HA specific IgG that were maintained over time. A peak was observed between 42 and 92 days post vaccination, and where the mice vaccinated with Pandemrix had significantly higher total IgG levels as compared to $\alpha$ MHCII-HA (Figure 1A). However, $\alpha$ MHCIIHA raised significantly higher antibody responses as compared to TIV, which only induced modest antibody responses in this system. After the peak, the responses seemed to reach a plateau from about day 106, and that were maintained for at least 180 days.

The antibody responses were highly strain specific, and only mild reactivity against the serologically different strain A/Puerto Rico/8/1934 (H1N1) (PR8) was detected after vaccination with Pandemrix or $\alpha$ MHCII-HA (Figure 1B). Interestingly, the difference between Pandemrix and $\alpha$ MHCII-HA seemed to be mostly due to a significantly higher amount of IgG1 antibodies following vaccination with Pandemrix (Figure 1C), while there were no significant differences in IgG2a levels (Figure 1D).

At day 180, mice were challenged with a lethal dose of influenza virus Cal07. Weight was monitored and used as an objective indicator of morbidity. As expected from the measured antibody responses, both $\alpha$ MHCII-HA and Pandemrix vaccination induced significantly improved protection as compared to TIV, characterized by near sterile protection and minimal weight loss after challenge (Figure 1E). In accordance with ethical requirements, mice that reached a $20 \%$ weight loss during the infection were euthanized. Importantly, none of the mice vaccinated with $\alpha$ MHCII-HA or Pandemrix reached this threshold (Figure 1F). Based on the low antibody levels associated with TIV, it may, however, be surprising that only $2 / 8$ mice in this group lost $20 \%$ or more of their weight, as opposed to the negative control groups where $8 / 8$ had to be euthanized. The mice receiving TIV lost weight until day 6 after infection, but from then on stabilized and regained weight (Figure 1F).

In sum, we observed that a single vaccination with either $\alpha \mathrm{MHCII}-\mathrm{HA}$ or Pandemrix could raise strong and long-lasting strain specific protective antibody responses against HA.

\section{Rapid Induction of Antibodies and Protection Against a Lethal Challenge With Influenza Virus}

Time is essential during a pandemic outbreak, with respect to both production time and the generation of protective immunity. Thus, we investigated how fast the different vaccines were able to induce protective immunity. $\mathrm{BALB} / \mathrm{c}$ mice were vaccinated once with $\alpha$ MHCII-HA, Pandemrix, TIV, or controls, and sera examined for antibody responses at day 7 after vaccination. Importantly, a majority of the mice vaccinated with either $\alpha \mathrm{MHCII}-\mathrm{HA}$ or Pandemrix had detectable levels of HA specific IgG, but there were also some that had not yet seroconverted (Figure 2A). TIV immunized mice did not display any serum antibodies at day 7. Interestingly, $\alpha \mathrm{MHCII}-$ HA was the only vaccine that could induced any antibody responses against the heterologous strain PR8, albeit only in 2 out of 16 mice in the group (Figure 2B). For homologous antibody responses against HA from Cal07, IgG1 and IgG2a levels were similar for Pandemrix and $\alpha \mathrm{MHCII-HA}$, but as was observed for total IgG, not all mice had seroconverted at this early time point (Figures 2C, D).

At day 8 after a single vaccination, mice were given a lethal dose of influenza Cal07 virus and weight was monitored. Interestingly, mice receiving $\alpha \mathrm{MHCII}-\mathrm{HA}$ lost significantly less 


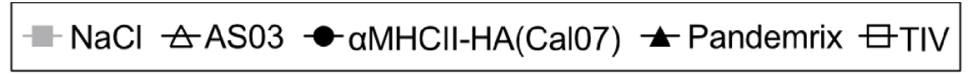

A

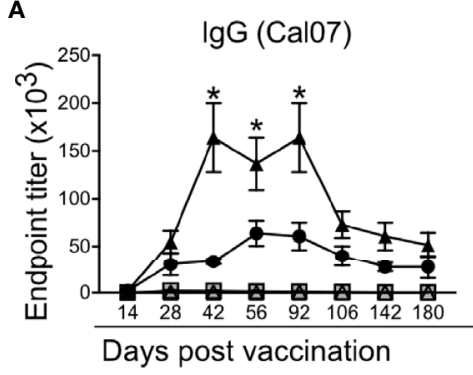

B

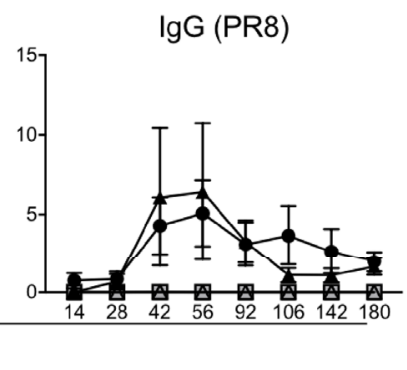

C

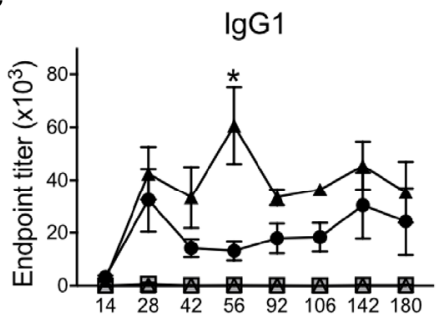

D

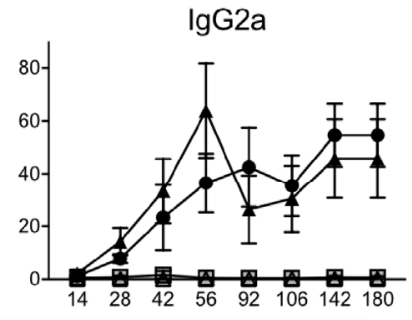

Days post vaccination

E

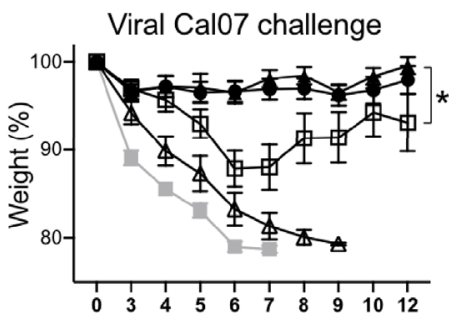

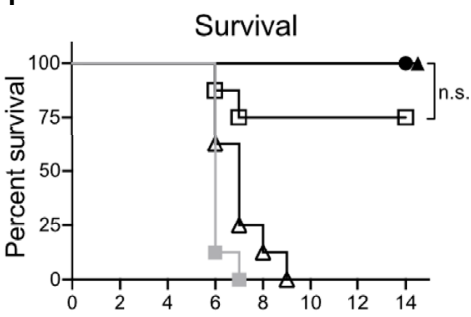

Days post viral challenge

FIGURE 1 | Long term antibody responses and protection after a single vaccination. Mice ( $\mathrm{n}=8 / \mathrm{group})$ were vaccinated i.m. with the indicated vaccines. (A-D) Serum antibodies were monitored up to 6 months after vaccination in ELISA for (A) total lgG against HA from Cal07, (B) total lgG against HA from PR8, (C) IgG1 against HA from Cal07, and (D) IgG2a against HA from Cal07. * $\mathrm{P}<0.05$ for $\alpha \mathrm{MHCll}-\mathrm{HA}$ versus Pandemrix. (E, F) At 180 days after vaccination, mice were challenged with $5 x_{5 D}$ dose of Cal07. (E) Weight was monitored. (F) Survival curve after challenge, defined by $20 \%$ weight loss. (A-E) Data shown are mean \pm SEM, *P $<0.05$ (two-way ANOVA) (F) *P $<0.05$ (Gehan-Breslow-Wilcoxon test). n.s., not significant.

weight as compared to mice vaccinated with Pandemrix, but there was a smaller initial weight loss also in this group (Figure 2E). The trend also held when assessing survival as defined by a $20 \%$ weight loss, with $\alpha$ MHCII-HA displaying a $25 \%$ relative improved survival rate, albeit not statistically significant, when compared to Pandemrix (Figure 2F). Mice vaccinated with TIV were not protected 7 days after challenge. None of the vaccines induced protection against the heterologous PR8 virus at day 8 post vaccination (Figures 2G, $\mathbf{H}$ ).

Taken together, we found that a single vaccination with either Pandemrix or $\alpha \mathrm{MHCII-HA}$ could rapidly lead to seroconversion that translated into protection already one week after vaccination. In addition, vaccination with the MHCII-targeted DNA vaccine significantly improved morbidity as compared to Pandemrix.

\section{Plasma Cells and High Avidity Antibodies After Vaccination}

To characterize the antibody response induced after vaccination with the different vaccines in detail, we first investigated the presence of plasma cells in bone marrow following vaccination. Thus, bone marrow was harvested from mice that had been vaccinated once with $\alpha$ MHCII-HA or Pandemrix. Single cell suspensions were prepared, and the number of anti-HA (Cal07) secreting cells assayed by ELISpot. At day 9, we detected no antiHA secreting cells in bone marrow, but by day 14 anti-HA secreting cells had formed for both these vaccines. Although low, at day 21 the levels had doubled, indicating a steady rise in antiHA secreting cells in response to vaccination. The development was similar for both $\alpha$ MHCII-HA and Pandemrix, but there was 


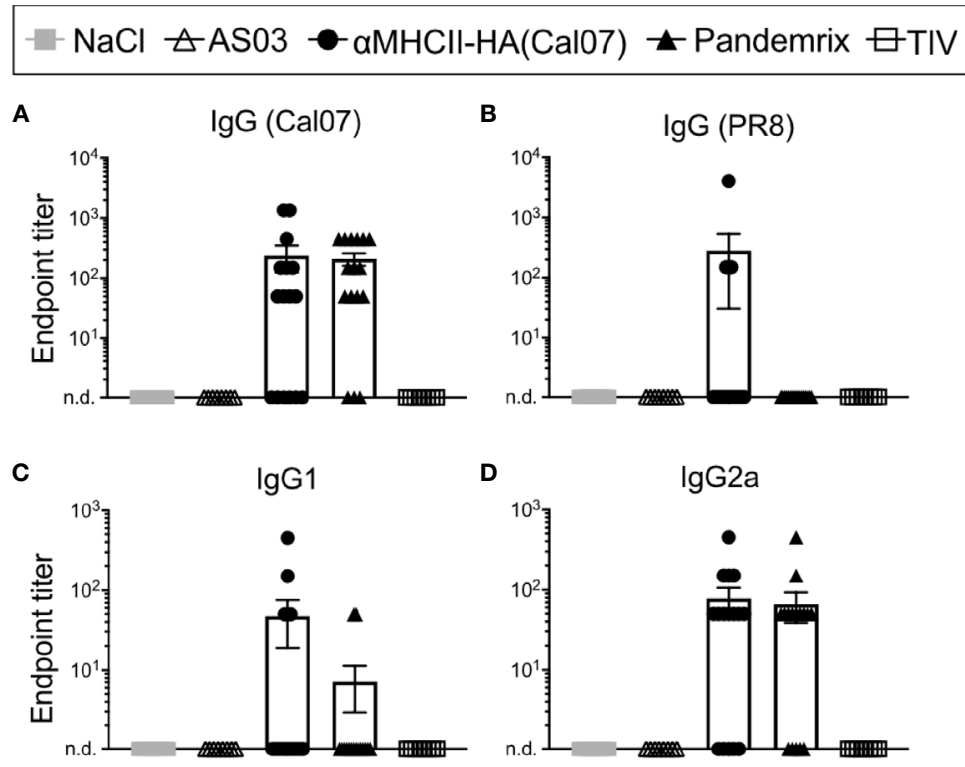

E

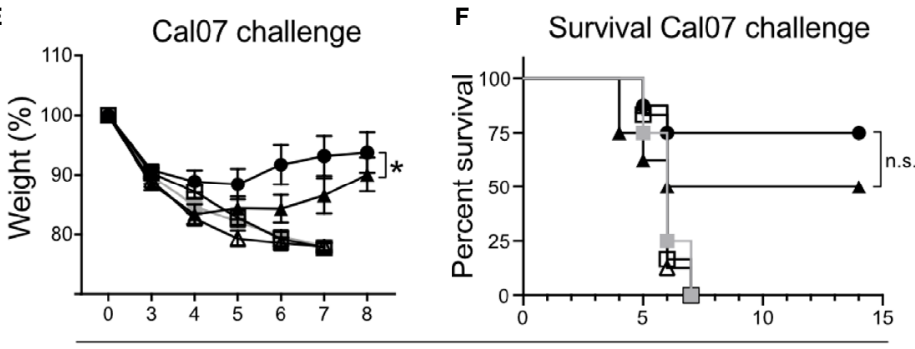

Days after challenge

G

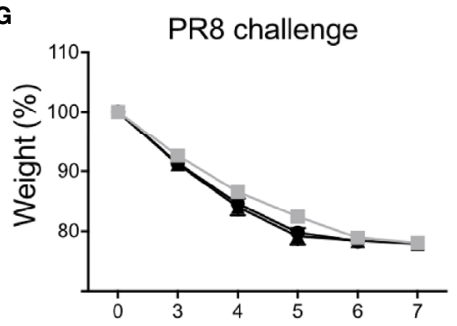

H Survival PR8 challenge

Days after challenge

FIGURE 2 | Rapid induction of antibodies and protection after vaccination. Mice were vaccinated i.m. with the indicated vaccines. (A-D) Serum antibodies were monitored at day 7 after vaccination in ELISA for (A) total IgG against HA from Cal07, (B) total lgG against HA from PR8, (C) IgG1 against HA from Cal07, and (D) IgG2a against HA from Cal07. Pandemrix, $\alpha$ MHCll-HA, and NaCl: $n=16 /$ group. ASO3 and TIV: $n=8 / g r o u p$. (E, F) At day 8 after vaccination, mice ( $n=8 /$ group) were challenged with a $5 \times$ LD $_{50}$ dose of influenza Cal07. (E) Weight was monitored. (F) Survival curve, as defined by a $20 \%$ weight loss. (G, H) At day 8 after vaccination, mice ( $\mathrm{n}=8$ /group) were challenged with a $5 \mathrm{XLD}_{50}$ dose of influenza PR8. (G) Weight was monitored. (F) Survival curve, as defined by a $20 \%$ weight loss. (A, D, E, G) Data shown are mean \pm SEM, *P $<0.05$ (two-way ANOVA); (F, H) *P $<0.05$ (Gehan-Breslow-Wilcoxon test). n.s., not significant.

a tendency that Pandemrix had slightly higher numbers of plasma cells at day 14 and 21 (Figure 3A).

To evaluate long-term responses, we also examined plasma cells at day 180 in bone marrow following vaccination with TIV, $\alpha \mathrm{MHCII}-\mathrm{HA}$, and Pandemrix. Interestingly, mice vaccinated with $\alpha \mathrm{MHCII}-\mathrm{HA}$ had significantly higher levels of plasma cells in the bone marrow as compared to mice receiving Pandemrix. Mice vaccinated with TIV did not show any plasma cells in response to vaccination after 180 days (Figure 3B).

Next, we wanted to investigate the avidity of the vaccine induced antibodies and set up an assay measuring the resistance to UREA wash as an indication of antibody binding avidity. In 
A

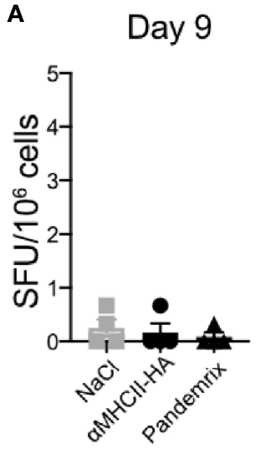

C

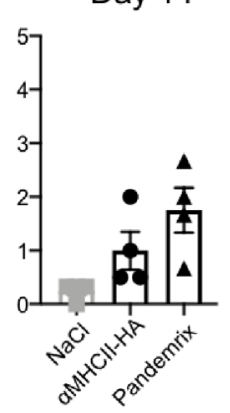

Day 21

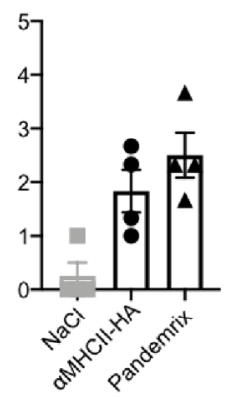

Day 14
B Day 180

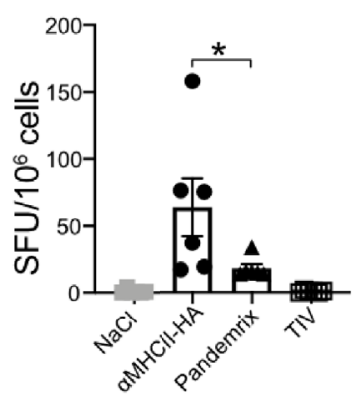

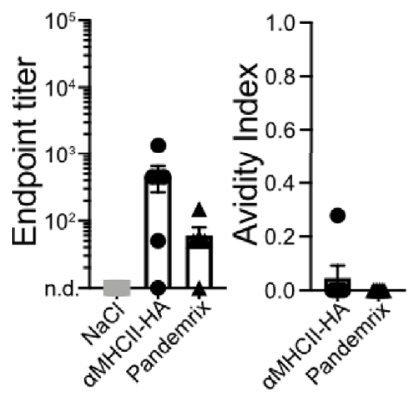
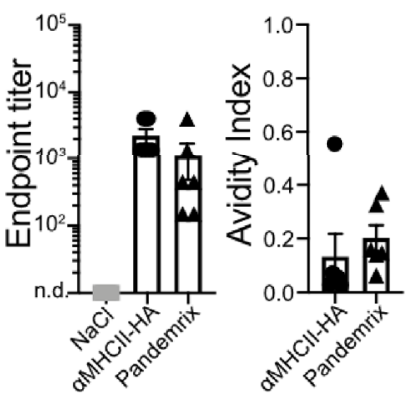

Day 21

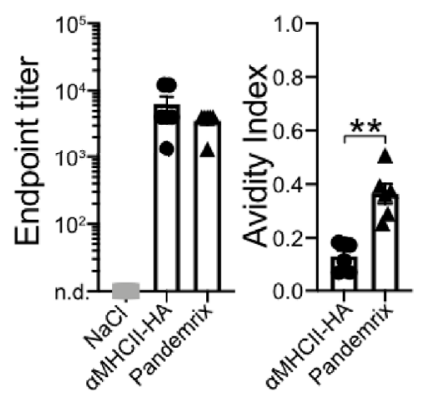

FIGURE 3 | Plasma cells in bone marrow and antibody avidity after vaccination. Mice ( $\mathrm{n}=6 / \mathrm{group})$ were vaccinated i.m. with the indicated vaccines. (A, B) Bone marrow (tibia) was harvested, and anti-HA secreting cells examined by ELISpot at (A) days 9, 14, and 21 after vaccination, or (B) day 180 post vaccination. (C) Antibody titers and avidity index of serum antibodies against HA as measured in ELISA from the indicated time points post vaccination. Data shown are mean \pm SEM, ${ }^{*} \mathrm{P}<0.05,{ }^{* *} \mathrm{P}<0.01$ (Mann-Whitney).

this assay, relative signals between washing with UREA or PBS in ELISA were compared, and an avidity index of 0 or 1 indicated no resistance or absolute resistance to UREA wash, respectively. Sera collected from mice at day 7, 14, and 21 post vaccination were assayed. In accordance with the above results from ELISA (Figures 1, 2), we did not observe significant differences in antibody titers for Pandemrix and $\alpha$ MHCII-HA. However, mice vaccinated with Pandemrix demonstrated a steady increase in serum antibodies with higher avidity towards HA from Cal07 (Figure 3C), mimicking the tendency observed for plasma cells in bone marrow (Figure 3A). At day 21, mice vaccinated with Pandemrix had significantly more serum antibodies with increased avidity as compared to mice vaccinated with $\alpha$ MHCII-HA, even though serum antibody levels were similar between the two vaccines (Figure $3 \mathbf{C}$ ).

In sum, we found that Pandemrix induced antibodies with higher avidity more rapidly than $\alpha$ MHCII-HA (day 21). However, with time (6 months) the level of plasma cells in response to $\alpha \mathrm{MHCII}-\mathrm{HA}$ vaccination was significantly higher than after vaccination with Pandemrix.

\section{Germinal Center Induction After Vaccination and HA Reactive B Cells}

The early presence of plasma cells in bone marrow could indicate a strong germinal center (GC) reaction to the vaccine antigen
(Figure 3A). Thus, we wanted to investigate the formation of GCs, as well as the presence of $\mathrm{HA}$ reactive $\mathrm{B}$ cells with a GC phenotype.

Mice were vaccinated once and draining lymph nodes (LN) (iliac) harvested on days 9, 14, and 21. Cells from the prepared single cell suspensions were stained for GC B cells (B220 ${ }^{+} \mathrm{CD} 38^{\text {lo }}$ $\mathrm{GL}^{+}$), identified by a recombinant HA probe (Figure 4A). A steady rise in HA reactivity among $B$ cells was observed from day 9 through day 21 post vaccination (Figure 4B). Mice receiving $\alpha$ MHCII-HA had GC B cells with a significantly elevated HA reactivity. However, Pandemrix induced a stronger GC reaction, and although the percentage of GC HA reactivity was lower in these mice, the total number of HA reactive GC B cells was significantly higher than after vaccination with $\alpha \mathrm{MHCII}-$ HA (Figure 4C).

The increased levels of GC B cells observed after vaccination with Pandemrix was likely augmented by the adjuvant AS03. Pandemrix is a split vaccine and also contains other antigens than HA. Thus, a new experiment was performed for day 21 post vaccination to also include an adjuvant control group and the non-adjuvanted split vaccine TIV. As expected, vaccination with $\alpha \mathrm{MHCII}-\mathrm{HA}$ again induced the highest percentages of HA reactive $\mathrm{B}$ cells with a GC phenotype in the LNs. The control groups vaccinated with $\mathrm{NaCl}$ or AS03 defined the background, and we observed that TIV induced low, but significant, levels of 


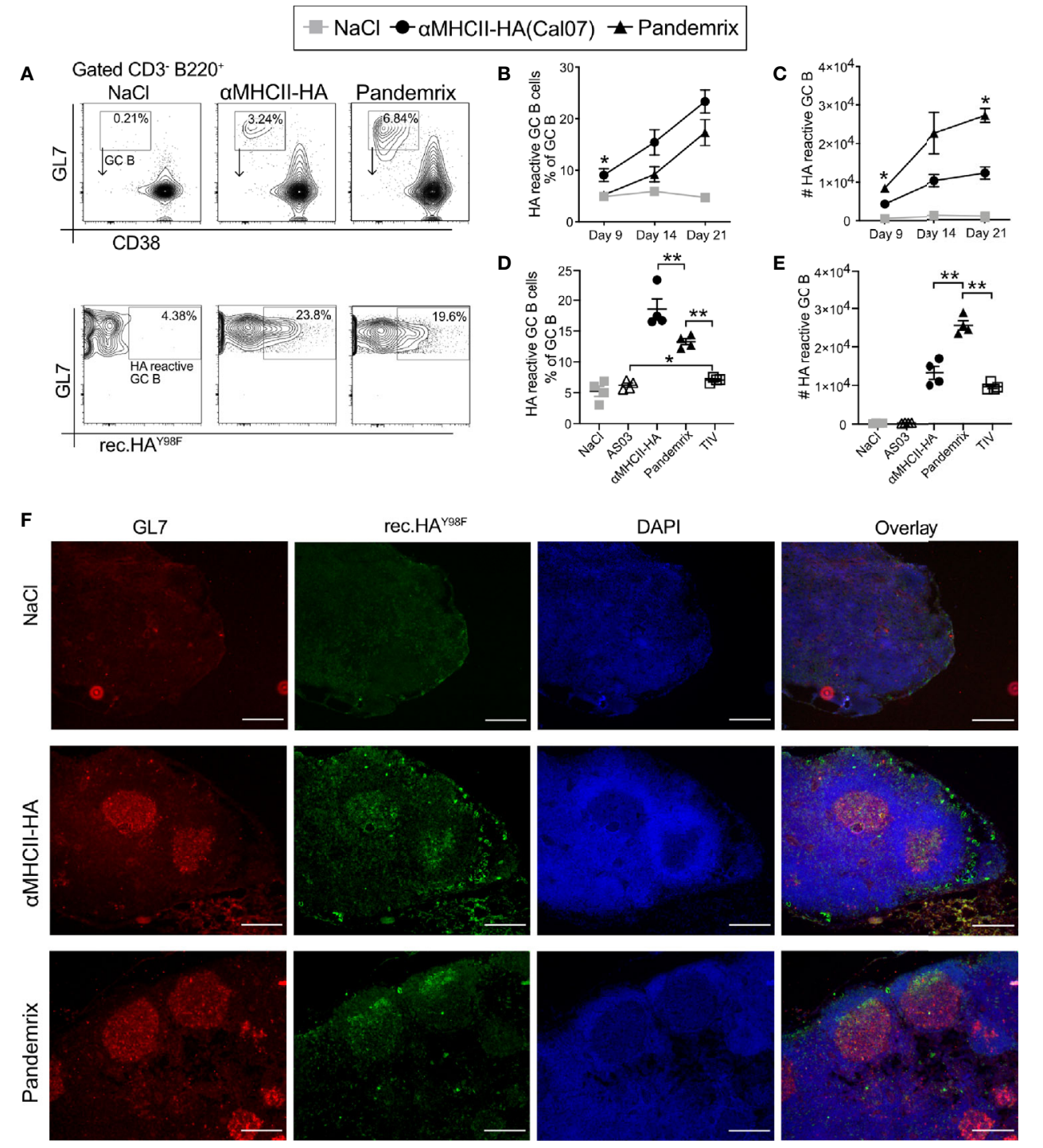

FIGURE 4 | Germinal center response and early formation of plasma cells after vaccination. Mice ( $\mathrm{n}=4 /$ group) were vaccinated i.m. with the indicated vaccines. (A-E) Draining lymph nodes (iliac) were harvested and examined for B cells (CD3 ${ }^{-}$B22 $\left.20^{+}\right)$, GC markers $\left(\mathrm{GL} 7^{+} \mathrm{CD} 38^{\mathrm{lo}}\right)$, and binding to a recombinant HA probe by flow cytometry. (A) Gating strategy. Representative flow charts are shown. (B) Fraction of HA reactive B cells with a GC phenotype on the indicated time points. (C) Absolute numbers of HA reactive GC B cells from draining LNs at the indicated time points. (D, E) In a new experiment, the GC response was investigated at 21 days post vaccination. (D) Fraction of HA reactive B cells with a GC phenotype. (E) Absolute numbers of HA reactive GC B cells. (F) Cryosections of draining lymph nodes harvested 21 days after vaccinations, and stained with GL7 (red), rHA ${ }^{\text {Y98F }}$ (green), and DAPI (blue). Scale bar is 200 $\mu$ m. Data shown are mean \pm SEM, ${ }^{*} \mathrm{P}<0.05,{ }^{* *} \mathrm{P}<0.01$ (Mann-Whitney).

HA reactive GC B cells (Figure 4D). When looking at the total number of HA reactive GC B cells, however, we again observed that Pandemrix induced the highest absolute numbers (Figure 4E).

The formation of GC was also evaluated by microscopic imaging of LNs harvested at day 21 after vaccination. The cryopreserved LN sections were stained with the GC activation marker GL7, the recombinant HA probe, and DAPI (Figure 4F). Multiple GC structures with HA reactivity were observed for the mice receiving $\alpha \mathrm{MHCII}-\mathrm{HA}$ or Pandemrix, in accordance with the flow cytometry data.
Taken together, the data demonstrate that vaccination with $\alpha$ MHCII-HA induced a response where the reactivity of GC B cells was focused on HA. Pandemrix induce a stronger immune response in total, and as such had a higher total number of GC B cells and HA reactive GC B cells.

\section{Strong Cytotoxic T-Cell Responses Induced by $\alpha \mathrm{MHCII-HA}$}

The fairly similar B cell activation and antibody levels observed after vaccination with Pandemrix or $\alpha$ MHCII-HA led to the 
question of whether differences in induction of cytotoxic $\mathrm{T}$ cells could explain the improved survival that was observed in mice at day 8 after vaccination with $\alpha$ MHCII-HA (Figure 2). Thus, single cell suspensions of splenocytes from naïve mice were loaded with $\mathrm{MHC}$ class I restricted peptides from $\mathrm{HA}$, influenza nucleoprotein (NP), or an irrelevant peptide as negative control, and stained with cell trace dyes. Next, the peptide loaded splenocytes were injected i.p. into mice immunized 9 days or 8 weeks prior with TIV, Pandemrix, $\alpha \mathrm{MHCII}-\mathrm{HA}$, or $\mathrm{NaCl}$. Following a $16 \mathrm{~h}$ incubation, spleens were harvested and the presence of transferred cells investigated by flow cytometry (Figure 5A). The ratios of HA or NP peptide loaded splenocytes to the irrelevant peptide negative control in $\mathrm{NaCl}$ treated mice was used as a reference to calculate the relative specific lysis of HA or NP peptide loaded cells in the vaccinated groups.

Importantly, mice vaccinated 9 days earlier with $\alpha \mathrm{MHCII}-$ HA displayed a strong cytotoxic response towards the HA peptide that was about 10 -fold higher than that observed in mice vaccinated with Pandemrix (Figure 5B). Vaccination with Pandemrix raised a similar cytotoxic response against both NP and HA, while $\alpha$ MHCII-HA, as expected, did not induce any cytotoxic activity towards the NP peptide (Figure 5C). Interestingly, TIV induced similar responses as Pandemrix
A

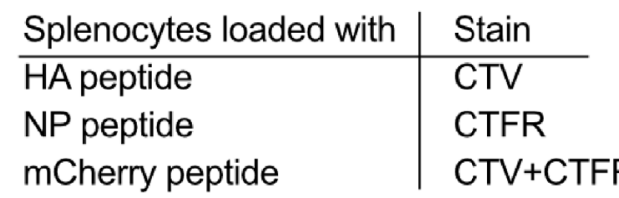

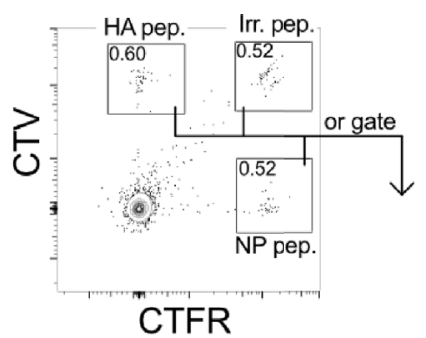

CTFR
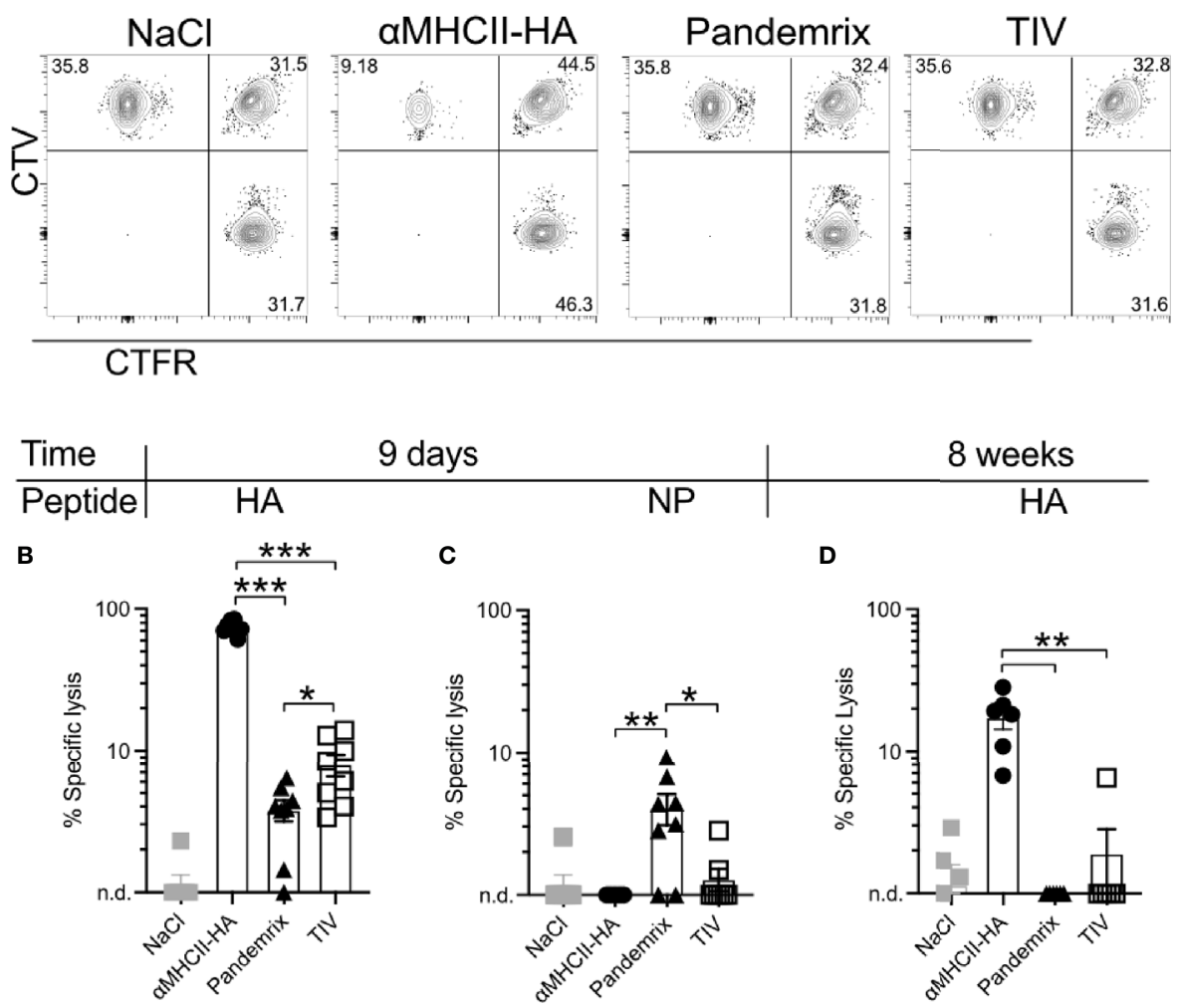

FIGURE 5 Short and long-term antigen-specific cytotoxic responses after vaccination. Mice ( $\mathrm{n}=6$-8/group) were vaccinated once i.m. with the indicated vaccines. After 9 days or 8 weeks, splenocytes from naïve mice were loaded with MHC class I restricted peptides from HA (IYSTVASSL), NP (RLIQNSLTIERMVLS), or irrelevant peptide. Cells were stained with CellTrace Violet (CTV), CellTrace Far Red (CTFR), or double stained with CTV and CTFR, respectively. Cells were mixed in equal ratios and injected i.v. to vaccinated mice. 16h later, spleens were harvested and the presence of peptide loaded splenocytes were assessed by flow cytometry. (A) Gating strategy for identification of transferred cells. (B) HA-specific lysis of splenocytes 9 days after vaccination. (C) NP-specific lysis of splenocytes 9 days after vaccination. (D) HAspecific lysis of splenocytes 8 weeks after vaccination. Data shown are mean $\pm \mathrm{SEM},{ }^{*} \mathrm{P}<0.05,{ }^{\star \star} \mathrm{P}<0.01,{ }^{\star \star \star} \mathrm{P}<0.001$ (Mann-Whitney). 
against both groups of peptides. In order to also examine the long-term cytotoxic potential, we set up a similar experiment 8 weeks post vaccination. The cytotoxic responses were markedly reduced in all the vaccine groups as compared to day 9, but the group vaccinated with $\alpha \mathrm{MHCII}-\mathrm{HA}$ maintained a significant and strong cytotoxic response (Figure 5D).

In sum, the data clearly demonstrated that $\alpha$ MHCII-HA induced a superior cytotoxic response both at early and later time points as compared to Pandemrix. The early induction of cytotoxic immunity could explain the improved protection observed after vaccination with $\alpha \mathrm{MHCII}-\mathrm{HA}$ and the viral challenge at 8 days post vaccination (Figure 2 ).

\section{Cytokine Secretion Following Vaccination}

$\mathrm{T}$ cells with an enhanced effector function have often been characterized by the dual secretion of two or more key cytokines (31), and the significant difference observed for cytotoxic responses between the vaccine groups (Figure 5) points towards different functional $\mathrm{T}$ cell profiles. Thus, we investigated the secretion of IFN $\gamma, \mathrm{IL}-2$, and TNF $\alpha$ in T cells from splenocytes harvested 21 days after a single vaccination, and stimulated ex vivo with HA (Cal07). In accordance with the improved cytotoxic response following vaccination with $\alpha$ MHCII-HA (Figure 5), the highest numbers of IFN $\gamma$, IL-2, and TNF $\alpha$ secreting CD4 T-cells were observed for this group
(Figure 6A). TIV induced somewhat higher numbers of cytokine secreting cells as compared to Pandemrix. The trend held also for double secreting CD4 T-cells. Triple secreting CD4 T-cells were not observed for any vaccine groups (Figure 6A). A similar trend was observed for the CD8 T-cells, but with somewhat higher levels (Figure 6B).

While the cytokine profiles indicated an increased level of effector T-cells, analysis of cells with effector memory $\left(\mathrm{T}_{\mathrm{EM}}\right)$ and central memory $\left(\mathrm{T}_{\mathrm{CM}}\right)$ phenotype was performed for CD4 and CD8 T-cells after ex vivo antigen stimulation. $\mathrm{T}_{\mathrm{EM}}$ was identified as $\mathrm{CD} 4 / \mathrm{CD}^{+} \mathrm{CD}^{+} 4^{+} \mathrm{CD}^{+} 4 \mathrm{~L}^{-}$cells and $\mathrm{T}_{\mathrm{CM}}$ was identified as CD4/CD8 ${ }^{+} \mathrm{CD}_{4}{ }^{+} \mathrm{CD} 4 \mathrm{~L}^{+}$cells. The $\mathrm{T}_{\mathrm{EM}}$ subsets were slightly elevated in mice receiving $\alpha \mathrm{MHCII}-\mathrm{HA}$ for both CD4 and CD8 $\mathrm{T}$-cells, whereas the other vaccine groups were similar to background (Figures 6C, D). $\mathrm{T}_{\mathrm{CM}}$ were not clearly elevated above background levels ( $\mathrm{NaCl}$ and $\mathrm{AS} 03$ ), although the percentage of CD8 $\mathrm{T}_{\mathrm{CM}}$ seemed to be higher in mice receiving TIV compared to $\alpha$ MHCII-HA (Figures 6E, F).

Taken together, the data confirms an increased potential for activation of multifunctional $\mathrm{T}$ cells following vaccination with aMHCII-HA, as compared to Pandemrix and TIV. Further, immunization with $\alpha \mathrm{MHCII}-\mathrm{HA}$ increased the $\mathrm{T}_{\mathrm{EM}}$ levels of both CD4 and CD8 T cells, indicating a strong protective effect. This is reflected in the highest survival rate after viral challenge compared across the vaccine platforms tested.

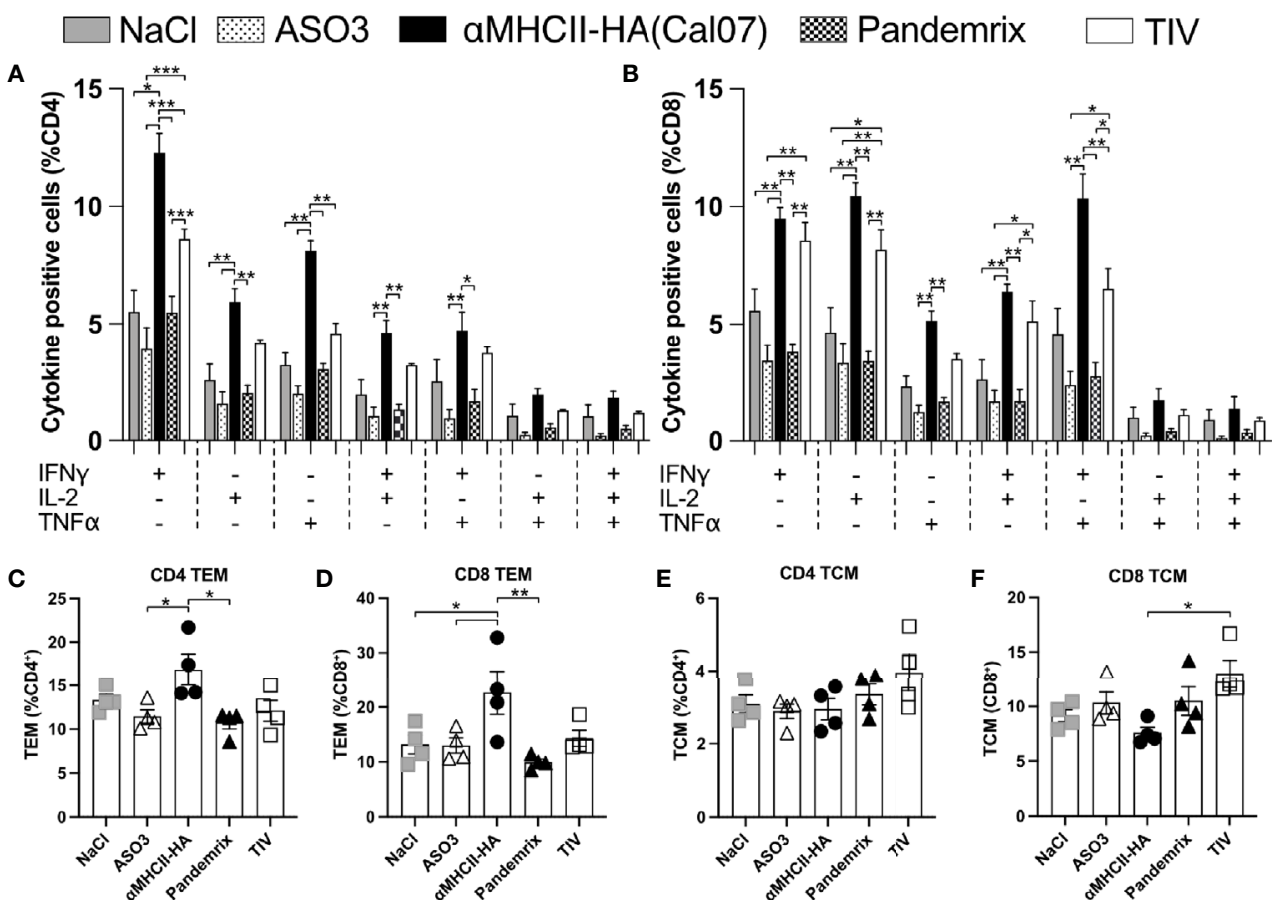

FIGURE 6 | Multifunctional T cell subsets after vaccination. Mice ( $n=4 /$ group) were vaccinated once i.m. with the indicated vaccines. 21 days after vaccination, splenocytes were harvested, and following overnight resting stimulated for $4 \mathrm{~h}$ with $\mathrm{HA}$ (CalO7) in the presence of a protein transport inhibitor. Single, double, or triple expression of cytokines IFN $\gamma$, IL-2, and TNF $\alpha$ were investigated for CD4 (A) and CD8 (B) T cell subsets. (C, D) Effector memory $\left(T_{E M}\right)$ and central memory (TCM) T cell subsets were defined as CD44 ${ }^{+}$CD64L', and CD44+ CD64L', respectively. (C) Presence of CD4 $T_{E M}$. (D) Presence of CD8 $T_{E M}$. (E) Presence of CD4 $T_{C M}$. (F) Presence of CD8 $\mathrm{T}_{\mathrm{CM}}$. Data shown are mean $\pm \mathrm{SEM},{ }^{\star} \mathrm{P}<0.05,{ }^{\star \star} \mathrm{P}<0.01,{ }^{\star \star \star} \mathrm{P}<0.001$ (Anova og Tukey's multiple comparison). 


\section{DISCUSSION}

The current SARS-CoV-2 pandemic has once again reminded us of our dependency on effective vaccines for control of a pandemic outbreak, and new vaccine platforms that efficiently can quench pandemic emergences are urgently needed. It is particularly important that the vaccines can be rapidly available for deployment in the population, and that protective immune responses are raised rapidly after vaccination.

In this study, we compared formation of immune responses in mice following vaccination with an MHCII-targeted DNA vaccine to that of conventional influenza vaccines. More specifically, we used an adjuvanted, inactivated split virion vaccine widely administered to counter the 2009 influenza pandemic (Pandemrix) and the corresponding conventional non-adjuvanted seasonal trivalent inactivated vaccine (TIV). A single delivery of the MHCII-targeted DNA vaccine raised HAspecific antibody responses with high avidity already after one week, similar to the responses induced by the adjuvanted Pandemrix, and both vaccines offered long-lasting protection against a lethal influenza challenge. Interestingly, the MHCIItargeted DNA vaccine proved even better than Pandemrix with respect to offering early protection against a lethal influenza challenge, probably due to the enhanced activation of cellular immunity after vaccination with $\alpha$ MHCII-HA.

DNA vaccines against influenza have been in development since the 1990's with promising data in pre-clinical models, but the reduced efficacy often observed in larger animals and humans has hampered progression to clinical application (17). New formulations such as lipid nanoparticles $(32,33)$, viral vector formulations $(34,35)$, and gene delivery methods (36) have increased vaccine efficacy, and a naked DNA vaccine from Inovio against SARS-CoV-2 just entered Phase 3 clinical testing (37).

The DNA vaccine format has several advantages for use in a pandemic setting, including advantageous price points and a cold chain independent distribution. A vaccine suited for pandemic preparedness against influenza should also be easily adaptable to match antigens of emerging strains and perform consistent across known influenza subtypes. Importantly, we have previously developed MHCII targeted DNA vaccines against several influenza subtypes, and observed a consistent and high immunogenicity in mice and larger animals $(22,23,38,39)$.

Besides the advantages of the DNA vaccine format, large-scale use of prophylactic DNA vaccines have also raised some safety concerns. Most pronounced is perhaps the potential for integration into host genomes $(40,41)$, antibiotic resistance (42), and DNA directed auto immunity (43). Fortunately, these phenomena have not been detected during clinical trials $(37,44-$ 47). DNA vaccines have thus far demonstrated a good safety profile during clinical evaluations, but, as we have recently been reminded (48), rare adverse events are difficult to detect prior to use in a larger population.

The main correlate of protection against influenza is neutralizing antibodies that can block viral entry, and influenza vaccines typically aim for induction of these. Here, the rapid rise observed in antibody levels after vaccination with $\alpha$ MHCII-HA or Pandemrix was supported by increases in GC B-cells and plasma cells in bone marrow. These parameters were also reflected by the avidity index scores of serum antibodies for the two vaccines. Pandemrix induced a slightly stronger response than the DNA vaccine for practically all antibody or B-cell related measurements at early time points, although not statistically significant. Further, Pandemrix induced a very high number of GC B-cells, but the total HA reactivity was increased with $\alpha$ MHCII-HA. The adjuvant AS03 likely contributed to the high number of GC B cells found in draining lymph nodes after Pandemrix vaccination. AS03 is optimized for increased influx of immune cells to lymph nodes and B cell recruitment (49), and presumably contributed to a significant increase in the number of $\mathrm{HA}$ reactive GC B cells and the tendency of higher plasma cell numbers in the bone marrow at similar time points. Fluorescent micrographs demonstrated that the GCs with HA reactivity were slightly enhanced following vaccination with Pandemrix as compared to $\alpha \mathrm{MHCII}-\mathrm{HA}$, in general accordance with GC B cell profile seen in the flow cytometry data (Figure 4).

Importantly, both Pandemrix and $\alpha \mathrm{MHCII}-\mathrm{HA}$ induced full protection against a lethal influenza challenge at 180 days post a single vaccination, with virtually no weight loss observed. Thus, the elevated IgG1 responses observed after vaccination with Pandemrix (Figure 1), as well as the increased avidity observed during the first weeks after vaccination (Figure 3), did not make a difference for the protective capacity long- or short-term as compared to MHCII-HA (Figures 1, 2). At day 180 post a single vaccination, we also observed lower levels of anti-HA secreting plasma cells in bone marrow after Pandemrix vaccination as compared to $\alpha \mathrm{MHCII}-\mathrm{HA}$. This also did not hamper protection, indicating that both vaccines were able to induce sufficient memory formation. TIV induced moderate long-term protection, in accordance with expectations for the single delivery of a non-adjuvanted vaccine administered to naïve mice.

In a pandemic setting, rapid formation of protective immunity is key. It is therefore important that both Pandemrix and $\alpha$ MHCII-HA were able to induce moderate protection against a lethal viral challenge already 8 days post a single vaccination. Interestingly, the DNA vaccine demonstrated a slight increase in survival as compared to Pandemrix, but significantly reduced morbidity. As expected, TIV did not induce any sign of immune resistance to challenge only 8 days after vaccination. At this time point, neither vaccine conferred sterilizing immunity against influenza. However, strong cytotoxic T-cell responses elicited by the MHCII targeted DNA vaccine are likely the underlying reason for the observed reduced morbidity in this vaccine group, as demonstrated by the significantly lower weight loss (Figure 2). This explanation was supported by observations of increased levels of CD4 and CD8 effector memory $\mathrm{T}$ cells after DNA vaccination. The clear differences in cytotoxicity observed ex vivo was also supported by the T cell cytokine profiles, with key cytokines such as IFN- $\gamma$, IL-2, and TNF- $\alpha$ elevated after DNA immunization both for the $\mathrm{CD} 8$ and CD4 T-cell compartment. The $\mathrm{T}$ cell responses raised at day 8 post vaccination were, however, not sufficient for 
protection against a different strain of influenza $\mathrm{H} 1 \mathrm{~N} 1$ (Figures 2G, H). However, we have previously found that the cellular immune responses induced by $\alpha \mathrm{MHCII}-\mathrm{HA}$ can protect against antigenically variable strains at 4 weeks after a single DNA vaccination $(22,50)$.

The hemagglutination inhibition (HI) assay is currently at the core for regulatory assessments of influenza vaccine immunogenicity (51). It evaluates the ability of antibodies to prevent virus from binding to red blood cells. Concerns about considering the $\mathrm{HI}$ titer a lone predictor of vaccine efficacy have been raised (52), especially for strains with a pandemic potential (53). During the past 20 years, several influenza subtypes (e.g. $\mathrm{H} 5, \mathrm{H} 7, \mathrm{H} 9$, and H10) have been demonstrated to breach the zoonotic barrier (54). The influenza virus is prone to antigenic drift, potentially hampering the efficacy of vaccine induced strain specific and neutralizing antibodies. Vaccines against influenza pandemics should therefore ideally be able to raise a combination of protective antibodies and $\mathrm{T}$ cell responses, offering at least some protection also against strain variants that may emerge. The ability of the MHCII-targeted DNA vaccine to raise a broader type of immune response, including both strong antibody responses and $\mathrm{T}$ cells, is encouraging in this respect.

For pandemic preparedness, one should consider the contribution from cytotoxic $\mathrm{T}$ cells induced solely by vaccines or in combination with pre-existing immunity. T cells often react to conserved epitopes that are shared among many different strains or even subtypes of influenza, offering immune resistance in the absence of effective antibodies (55). An ideal vaccine for pandemic preparedness should therefor activate both arms of the immune system and induce neutralizing antibodies as well as cytotoxic $\mathrm{T}$ cell responses. $\mathrm{T}$ cell mediated immunity cannot confer sterilizing immunity, but the broader responses to more conserved epitopes in the virion may prevent progression to severe morbidity or mortality. Thus, it may be important to establish $\mathrm{T}$ cell based correlates of protection against disease for improved evaluation and approval of influenza vaccines.

In summary, DNA vaccines targeting $\mathrm{HA}$ to $\mathrm{MHCII}$ molecules demonstrated comparable antibody responses and efficacy to Pandemrix in a mouse model. A noteworthy difference between these two vaccines was the cytotoxic T-cell response after vaccination with $\alpha$ MHCII-HA, that likely improved symptomatic disease at an early time-point after a single vaccination. Due to the many advantages of the DNA

\section{REFERENCES}

1. Andersen P, Scriba TJ. Moving Tuberculosis Vaccines From Theory to Practice. Nat Rev Immunol (2019) 19:550-62. doi: 10.1038/s41577-019-0174-Z

2. Orenstein WA, Ahmed R. Simply Put: Vaccination Saves Lives. Proc Natl Acad Sci U S A (2017) 114:4031-3. doi: 10.1073/pnas.1704507114

3. Blasio BF, Iversen BG, Tomba GS. Effect of Vaccines and Antivirals During the Major 2009 A(H1N1) Pandemic Wave in Norway-and the Influence of Vaccination Timing. PLoS One (2012) 7:e30018. doi: 10.1371/journal.pone.0030018

4. Paules CI, Fauci AS. Influenza Vaccines: Good, But We Can Do Better. J Infect Dis (2019) 219:S1-4. doi: 10.1093/infdis/jiy633

5. Conway JM, Tuite AR, Fisman DN, Hupert N, Meza R, Davoudi B, et al. Vaccination Against 2009 Pandemic H1N1 in a Population Dynamical Model vaccine format over egg-based split virus vaccines, these data confirms the relevance of DNA vaccines as an attractive approach for pandemic preparedness.

\section{DATA AVAILABILITY STATEMENT}

The original contributions presented in the study are included in the article/supplementary material. Further inquiries can be directed to the corresponding author.

\section{ETHICS STATEMENT}

The animal study was reviewed and approved by Norwegian Food Safety Authority.

\section{AUTHOR CONTRIBUTIONS}

GG, SM, TKA, and BB conceived and designed experiments. TKA, JB, SM, FO, and GG performed and analyzed experiments. TKA and GG wrote the paper. All authors edited and commented on the paper. All authors contributed to the article and approved the submitted version.

\section{FUNDING}

The work has been funded by the Research Council of Norway, as well as Helse Sør-Øst.

\section{ACKNOWLEDGMENTS}

We thank Kristina Randjelovic for technical help. Mice were housed at the Department of Comparative Medicine, Oslo University Hospital, and at the Animal Core Facility of the Norwegian Insitute of Public Health. We gratefully acknowledge the technical help from department staff at these two locations.

of Vancouver, Canada: Timing Is Everything. BMC Public Health (2011) 11:932. doi: 10.1186/1471-2458-11-932

6. Matrajt L, Halloran ME, Longini IMJr. Optimal Vaccine Allocation for the Early Mitigation of Pandemic Influenza. PLoS Comput Biol (2013) 9: e1002964. doi: 10.1371/journal.pcbi.1002964

7. Mylius SD, Hagenaars TJ, Lugner AK, Wallinga J. Optimal Allocation of Pandemic Influenza Vaccine Depends on Age, Risk and Timing. Vaccine (2008) 26:3742-9. doi: 10.1016/j.vaccine.2008.04.043

8. Krammer F, Palese P. Advances in the Development of Influenza Virus Vaccines. Nat Rev Drug Discov (2015) 14:167-82. doi: 10.1038/nrd4529

9. Baden LR, El Sahly HM, Essink B, Kotloff K, Frey S, Novak R, et al. Efficacy and Safety of the mRNA-1273 SARS-CoV-2 Vaccine. N Engl J Med (2021) 384:403-16. doi: 10.1056/NEJMoa2035389 
10. Polack FP, Thomas SJ, Kitchin N, Absalon J, Gurtman A, Lockhart S, et al. Safety and Efficacy of the BNT162b2 mRNA Covid-19 Vaccine. N Engl J Med (2020) 383:2603-15. doi: 10.1056/NEJMoa2034577

11. Voysey M, Clemens SAC, Madhi SA, Wecky LY, Folegatti PM, Aley PK, et al. Safety and Efficacy of the ChAdOx1 Ncov-19 Vaccine (AZD1222) Against SARS-CoV-2: An Interim Analysis of Four Randomised Controlled Trials in Brazil, South Africa, and the UK. Lancet (2021) 397:99-111. doi: 10.1016/ S0140-6736(20)32661-1

12. Kutzler MA, Weiner DB. DNA Vaccines: Ready for Prime Time? Nat Rev Genet (2008) 9:776-88. doi: 10.1038/nrg2432

13. Fernando GJ, Zhang J, Ng H-I, Haigh OL, Yukiko SR, Kendall MAF. Influenza Nucleoprotein DNA Vaccination by a Skin Targeted, Dry Coated, Densely Packed Microprojection Array (Nanopatch) Induces Potent Antibody and CD8(+) T Cell Responses. J Control Release (2016) 237:35-41. doi: 10.1016/ j.jconrel.2016.06.045

14. Song J-M, Kim Y-C, Compans RW, Prausnitz MR, Kang S-M. DNA Vaccination in the Skin Using Microneedles Improves Protection Against Influenza. Mol Ther (2012) 20:1472-80. doi: 10.1038/mt.2012.69

15. Diehl MC, Lee JC, Daniels SE, Tebas P, Khan AS, Giffear M, et al. Tolerability of Intramuscular and Intradermal Delivery by CELLECTRA((R)) Adaptive Constant Current Electroporation Device in Healthy Volunteers. Hum Vaccin Immunother (2013) 9:2246-52. doi: 10.4161/hv.24702

16. Graham BS, Enama ME, Nason MC, Gordon IJ, Peel SA, Ledgerwood JE, et al. DNA Vaccine Delivered by a Needle-Free Injection Device Improves Potency of Priming for Antibody and CD8+ T-Cell Responses After Rad5 Boost in a Randomized Clinical Trial. PLoS One (2013) 8:e59340. doi: 10.1371/journal.pone.0059340

17. Lee LYY, Izzard L, Hurt AC. A Review of DNA Vaccines Against Influenza. Front Immunol (2018) 9:1568. doi: 10.3389/fimmu.2018.01568

18. Pollard AJ, Launay O, Lelievre J-D, Lacabaratz C, Grande S, Goldstein N, et al. Safety and Immunogenicity of a Two-Dose Heterologous Ad26.ZEBOV and MVA-BN-Filo Ebola Vaccine Regimen in Adults in Europe (EBOVAC2): A Randomised, Observer-Blind, Participant-Blind, Placebo-Controlled, Phase 2 Trial. Lancet Infect Dis (2021) 21:493-506. doi: 10.1016/S1473-3099(20)30476-X

19. Wolf J, Jannat R, Dubey S, Troth S, Onorato MT, Coller B-A, et al. Development of Pandemic Vaccines: ERVEBO Case Study. Vaccines (Basel) (2021) 9. doi: 10.3390/vaccines 9030190

20. Cines DB, Bussel JB. SARS-CoV-2 Vaccine-Induced Immune Thrombotic Thrombocytopenia. N Engl J Med (2021) 384:2254-6. doi: 10.1056/NEJMe2106315

21. Fredriksen AB, Sandlie I, Bogen B. DNA Vaccines Increase Immunogenicity of Idiotypic Tumor Antigen by Targeting Novel Fusion Proteins to AntigenPresenting Cells. Mol Ther (2006) 13:776-85. doi: 10.1016/j.ymthe.2005.10.019

22. Grodeland G, Mjaaland S, Roux KH, Fredriksen AB, Bogen B. DNA Vaccine That Targets Hemagglutinin to MHC Class II Molecules Rapidly Induces Antibody-Mediated Protection Against Influenza. J Immunol (2013) 191:3221-31. doi: 10.4049/jimmunol.1300504

23. Grodeland G, Fredriksen AB, Løset GÅ, Vikse E, Fugger L, Bogen B. Antigen Targeting to Human HLA Class II Molecules Increases Efficacy of DNA Vaccination. J Immunol (2016) 197:3575-85. doi: 10.4049/jimmunol.1600893

24. Grodeland G, Mjaaland S, Tunheim G, Fredriksen AB, Bogen B. The Specificity of Targeted Vaccines for APC Surface Molecules Influences the Immune Response Phenotype. PLoS One (2013) 8:e80008. doi: 10.1371/journal.pone.0080008

25. Fossum E, Grødeland G, Terhorst D, Tveita AA, Vikse E, Mjaaland S, et al. Vaccine Molecules Targeting Xcrl on Cross-Presenting DCs Induce Protective CD8+ T-Cell Responses Against Influenza Virus. Eur J Immunol (2015) 45:624-35. doi: 10.1002/eji.201445080

26. Grodeland G, Fossum E, Bogen B. Polarizing T and B Cell Responses by APC-Targeted Subunit Vaccines. Front Immunol (2015) 6:367. doi: 10.3389/fimmu.2015.00367

27. Braathen R, Spång HCL, Lindeberg MM, Fossum E, Grødeland G, Fredriksen $\mathrm{AB}$, et al. The Magnitude and IgG Subclass of Antibodies Elicited by Targeted DNA Vaccines Are Influenced by Specificity for APC Surface Molecules. Immunohorizons (2018) 2:38-53. doi: 10.4049/immunohorizons.1700038

28. Grodeland G, Bogen B. Efficient Vaccine Against Pandemic Influenza: Combining DNA Vaccination and Targeted Delivery to MHC Class II Molecules. Expert Rev Vaccines (2015) 14:805-14. doi: 10.1586/14760584.2015.1029919

29. Frank GM, Angeletti D, Ince WL, Gibbs JS, Khurana S, Wheatley AK, et al. A Simple Flow-Cytometric Method Measuring B Cell Surface Immunoglobulin Avidity Enables Characterization of Affinity Maturation to Influenza A Virus. MBio (2015) 6:e01156. doi: 10.1128/mBio.01156-15
30. Durward M, Harms J, Splitter G. Antigen Specific Killing Assay Using CFSE Labeled Target Cells. J Vis Exp (2010) e2250. doi: 10.3791/2250

31. Seder RA, Darrah PA, Roederer M. T-Cell Quality in Memory and Protection: Implications for Vaccine Design. Nat Rev Immunol (2008) 8:247-58. doi: $10.1038 /$ nri2274

32. Francis JE, Skakic I, Dekiwadia C, Shukla R, Taki AC, Walduck A, et al. Solid Lipid Nanoparticle Carrier Platform Containing Synthetic TLR4 Agonist Mediates Non-Viral DNA Vaccine Delivery. Vaccines (Basel) (2020) 8. doi: $10.3390 /$ vaccines 8030551

33. Mucker EM, Karmali PP, Vega J, Kwilas SA, Wu H, Joselyn M, et al. Lipid Nanoparticle Formulation Increases Efficiency of DNA-Vectored Vaccines/ Immunoprophylaxis in Animals Including Transchromosomic Bovines. Sci Rep (2020) 10:8764. doi: 10.1038/s41598-020-65059-0

34. de Vries RD, Rimmelzwaan GF. Viral Vector-Based Influenza Vaccines. Hum Vaccin Immunother (2016) 12:2881-901. doi: 10.1080/21645515.2016.1210729

35. Rollier CS, Spencer AJ, Sogaard KC, Honeycutt J, Furze J, Bregu M, et al. Modification of Adenovirus Vaccine Vector-Induced Immune Responses by Expression of a Signalling Molecule. Sci Rep (2020) 10:5716. doi: 10.1038/ s41598-020-61730-8

36. Suschak JJ, Williams JA, Schmaljohn CS. Advancements in DNA Vaccine Vectors, non-Mechanical Delivery Methods, and Molecular Adjuvants to Increase Immunogenicity. Hum Vaccin Immunother (2017) 13:2837-48. doi: $10.1080 / 21645515.2017 .1330236$

37. Tebas P, Yang S, Boyer JD, Reuschel EL, Patel A, Christensen-Quick A, et al. Safety and Immunogenicity of INO-4800 DNA Vaccine Against SARS-CoV2: A Preliminary Report of an Open-Label, Phase 1 Clinical Trial. EClinicalMedicine (2021) 31:100689. doi: 10.1016/j.eclinm.2020.100689

38. Andersen TK, Zhou F, Cox R, Bogen B, Grodeland G. A DNA Vaccine That Targets Hemagglutinin to Antigen-Presenting Cells Protects Mice Against H7 Influenza. J Virol (2017) 91:e01340-17. doi: 10.1128/JVI.01340-17

39. Anderson AM, Baranowska-Hustad M, Braathen R, Grodeland G, Bogen B. Simultaneous Targeting of Multiple Hemagglutinins to APCs for Induction of Broad Immunity Against Influenza. J Immunol (2018) 200:2057-66. doi: 10.4049/jimmunol.1701088

40. Langer B, Renner M, Scherer J, Schule S, Cichutek K. Safety Assessment of Biolistic DNA Vaccination. Methods Mol Biol (2013) 940:371-88. doi: 10.1007/978-1-62703-110-3_27

41. Strain AJ. The Uptake and Fate of Exogenous Cellular DNA in Mammalian Cells. Dev Biol (Basel) (2006) 123:23-8.

42. Williams JA. Improving DNA Vaccine Performance Through Vector Design. Curr Gene Ther (2014) 14:170-89. doi: 10.2174/156652321403140819122538

43. MacColl G, Bunn C, Goldspink G, Bouloux P, Gorecki DC. Intramuscular Plasmid DNA Injection can Accelerate Autoimmune Responses. Gene Ther (2001) 8:1354-6. doi: 10.1038/sj.gt.3301537

44. Carter C, Houser KV, Yamshchikov GV, Bellamy AR, May J, Enama ME, et al. Safety and Immunogenicity of Investigational Seasonal Influenza Hemagglutinin DNA Vaccine Followed by Trivalent Inactivated Vaccine Administered Intradermally or Intramuscularly in Healthy Adults: An Open-Label Randomized Phase 1 Clinical Trial. PLoS One (2019) 14: e0222178. doi: 10.1371/journal.pone.0222178

45. Danko JR, Kochel T, Teneza-Mora N, Luke TC, Raviprakash K, Sun P, et al. Safety and Immunogenicity of a Tetravalent Dengue DNA Vaccine Administered With a Cationic Lipid-Based Adjuvant in a Phase 1 Clinical Trial. Am J Trop Med Hyg (2018) 98:849-56. doi: 10.4269/ajtmh.17-0416

46. Elizaga ML, Li SS, Kochar NK, Wilson GJ, Allen MA, Tieu HVN, et al. Safety and Tolerability of HIV-1 Multiantigen pDNA Vaccine Given With IL-12 Plasmid DNA via Electroporation, Boosted With a Recombinant Vesicular Stomatitis Virus HIV Gag Vaccine in Healthy Volunteers in a Randomized, Controlled Clinical Trial. PLoS One (2018) 13:e0202753. doi: 10.1371/journal.pone.0202753

47. Richie TL, Charoenvit Y, Wang R, Epstein JE, Hedstrom RC, Kumar S, et al. Clinical Trial in Healthy Malaria-Naive Adults to Evaluate the Safety, Tolerability, Immunogenicity and Efficacy of MuStDO5, a Five-Gene, Sporozoite/Hepatic Stage Plasmodium Falciparum DNA Vaccine Combined With Escalating Dose Human GM-CSF DNA. Hum Vaccin Immunother (2012) 8:1564-84. doi: 10.4161/hv.22129

48. Schultz NH, Sørvoll IH, Michelsen AE, Munthe LA, Lund-Johansen F, Ahlen MT, et al. Thrombosis and Thrombocytopenia After ChAdOx1 Ncov-19 Vaccination. N Engl J Med (2021) 384:2124-30. doi: 10.1056/NEJMoa2104882 
49. Galson JD, Truck J, Kelly DF, van der Most R. Investigating the Effect of AS03 Adjuvant on the Plasma Cell Repertoire Following Ph1n1 Influenza Vaccination. Sci Rep (2016) 6:37229. doi: 10.1038/srep37229

50. Lambert L, Kinnear E, McDonald JU, Grodeland G, Bogen B, Stubsrud E, et al. DNA Vaccines Encoding Antigen Targeted to MHC Class II Induce Influenza-Specific CD8(+) T Cell Responses, Enabling Faster Resolution of Influenza Disease. Front Immunol (2016) 7:321. doi: 10.3389/ fimmu.2016.00321

51. Committee for Medicinal Products for Human Use. Guideline on Influenza Vaccines: Non-Clinical and Clinical Module. EMA/CHMP/VWP/457259/2014. European Medicines Agency (2016).

52. Cox RJ. Correlates of Protection to Influenza Virus, Where do We Go From Here? Hum Vaccin Immunother (2013) 9:405-8. doi: 10.4161/hv.22908

53. Krammer F, Cox RJ. The Emergence of H7N9 Viruses: A Chance to Redefine Correlates of Protection for Influenza Virus Vaccines. Expert Rev Vaccines (2013) 12:1369-72. doi: 10.1586/14760584.2013.850036

54. Bailey ES, Fieldhouse JK, Choi JY, Gray GC. A Mini Review of the Zoonotic Threat Potential of Influenza Viruses, Coronaviruses, Adenoviruses, and Enteroviruses. Front Public Health (2018) 6:104. doi: 10.3389/fpubh.2018.00104

55. Koutsakos M, Illing PT, Nguyen THO, Mifsud NA, Crawford JC, Rizzetto S, et al. Human CD8(+) T Cell Cross-Reactivity Across Influenza A, B and C Viruses. Nat Immunol (2019) 20:613-25. doi: 10.1038/s41590-019-0320-6
Conflict of Interest: GG and BB are inventors on a patent applications filed on an HLAII-specific targeting moiety according to institutional rules through the TTO offices of the University of Oslo and Oslo University Hospital. Further, BB is inventor of the core patent of Vaccibody AS, and hold shares in the company.

The remaining authors declare that the research was conducted in the absence of any commercial or financial relationships that could be construed as a potential conflict of interest.

Publisher's Note: All claims expressed in this article are solely those of the authors and do not necessarily represent those of their affiliated organizations, or those of the publisher, the editors and the reviewers. Any product that may be evaluated in this article, or claim that may be made by its manufacturer, is not guaranteed or endorsed by the publisher.

Copyright (C) 2021 Andersen, Bodin, Oftung, Bogen, Mjaaland and Grødeland. This is an open-access article distributed under the terms of the Creative Commons Attribution License (CC BY). The use, distribution or reproduction in other forums is permitted, provided the original author(s) and the copyright owner(s) are credited and that the original publication in this journal is cited, in accordance with accepted academic practice. No use, distribution or reproduction is permitted which does not comply with these terms. 